\title{
EN DEFENSA DE LA PROPIEDAD INDEBIDAMENTE EMBARGADA
}

\begin{abstract}
AlEXANDER Rioja BERMÚdEZ*
Resumen

En el presente artículo se desarrolla doctrinaria y jurisprudencialmente la figura de la tercería de propiedad como una institución que garantiza el derecho de propiedad de quien se ve afectado ante una medida cautelar de embargo en un proceso en el cual no es parte. De esta forma analiza los fundamentos y condiciones que se requieren para efectivizar la institución materia de estudio.
\end{abstract}

Palabras clave: Tercería - Propiedad - Embargo - Derecho de propiedad.

\begin{abstract}
This article develops the existing scholar doctrine and case law on third party claims to ownership as an institution that guarantees the ownership rights of the person affected by the precautionary measure of attachment in proceedings in which he is not a party, thereby analyzing the grounds and conditions required to enforce said institution.
\end{abstract}

Key words: Outsourcing - Third party claims to ownership - Attachment Ownership Rights.

\section{Sumario}

1. Introducción. 2. Etimología. 2.1. Antecedentes históricos. 3. Concepto. 3.1. Desde el punto de vista sustantivo. 3.2. Desde el punto de vista procesal. 4. Fundamento. 4.1. La tercería en términos amplios. 4.2. Términos a diferenciar. 5. Competencia en materia de tercería. 6. Clases. 6.1. Acción de tercería de propiedad o de dominio. 6.1.1. Concepto. 6.1.2. Fundamento. 6.2. Condiciones de la acción de tercería de dominio. 6.2.1. Presupuestos relativos a la admisibilidad de la demanda. 6.2.1.1. Un principio de prueba por escrito del fundamento de la pretensión del tercerista. 6.2.1.2. La existencia del embargo sobre bienes y derechos. 6.2.1.3. Prestación de caución. 6.2.2. Presupuestos relativos al fondo de la pretensión. 6.2.2.1. No tener la condición de parte en la ejecución. 6.2.2.2. Tener la calidad de propietario o titular del bien o derecho materia de embargo. 6.2.2.3. Adquisición del bien o derecho con anterioridad a la afectación del embargo. 6.3. Tercería de mejor derecho o tercería de pago. 6.3.1. Concepto. 7. Oportunidad. 8. Efectos de la tercería de propiedad. 9. Conclusiones.

* Juez Especializado Titular de la Corte Superior de Justicia de Loreto-Poder Judicial del Perú. 


\section{INTRODUCCIÓN}

Las tercerías sean las de dominio como las de mejor derecho, se caracterizan por ser un instrumento de protección previstas en nuestro ordenamiento jurídico y que se encuentran a disposición de terceros afectados por un proceso de ejecución en el que no son parte, permitiéndoles hacer valer sus derechos e intereses y evitar de esta manera los efectos negativos de la ejecución.

El sub capítulo 5 del Título II, Sección quinta del Código Procesal Civil regula dentro de los llamados procesos que se tramitan en la vía abreviada la figura de la tercería. La cual se sustenta en el hecho por el cual se busca que la eficacia de una medida cautelar o para la ejecución respecto de determinados bienes que no le pertenezcan al ejecutado sea dejada sin efecto, lo que le da sentido a la figura de la tercería de dominio como instrumento del titular del bien materia de carga para hacer valer sus derechos.

La Tercería de dominio aparece en los casos de embargo preventivo y en el procedimiento de ejecución sobre bienes hipotecados o pignorados.

La Tercería de mejor derecho aparece en los supuestos en los que el tercero, ajeno al proceso de ejecución, afirma ser titular de un derecho de crédito preferente al presentado por el acreedor-ejecutante y solicita al juez que se pronuncie sobre qué crédito es preferente, para que éste sea satisfecho, en primer lugar, con las sumas obtenidas del embargo.

Así el artículo $533^{\circ}$ de la norma procesal civil establece que: "La tercería se entiende con el demandante y el demandado, y sólo puede fundarse en la propiedad de los bienes afectados judicialmente por medida cautelar o para la ejecución; o en el derecho preferente a ser pagado con el precio de tales bienes. Sin perjuicio de lo señalado, puede fundarse en la propiedad de bienes afectados con garantías reales, cuando el derecho del tercerista se encuentra inscrito con anterioridad a dicha afectación".

En tal sentido resulta que esta figura constituye el medio más específico para impugnar una medida cautelar o para su ejecución por el titular real de los bienes trabados indebidamente, o poder garantizar su derecho preferente. Se trata, como después analizaremos, de un procedimiento especial, de carácter incidental, pero con tramitación propia, siguiendo los cauces del llamado proceso declarativo. Su carácter incidental resulta de su vinculación al procedimiento de ejecución donde se ha dispuesto el gravamen, pero tiene un objeto propio, de regulación especial, al margen de las "cuestiones 
incidentales" reguladas en los artículos $533^{\circ}$ y siguientes que se han de analizar brevemente por cuestiones de tiempo y espacio.

\section{ETIMOLOGÍA}

\subsection{Antecedentes históricos}

No se han encontrado antecedentes de las tercerías en el derecho romano, ni en el medieval, ni en el canónico, las leyes españolas desde el futuro juzgo hasta la novísima recopilación, tampoco las reglamentan, solo en la ley de enjuiciamiento española de 1855, se encuentran algunos antecedentes de ordenamiento jurídico.

La tercería de propiedad es aquella acción por la cual el propietario de un bien, afectado equivocadamente por una medida cautelar o de ejecución dictada en otro proceso para hacer efectiva una obligación ajena y en el cual no es parte, recurre ante el órgano jurisdiccional alegando que tiene la propiedad de los bienes embargados a fin de lograr la desafectación del bien.

Para Lama ${ }^{1}$, los bienes del deudor responden por sus obligaciones. Este principio, vigente desde la Roma imperial, impide al acreedor el "ataque" a los bienes que pertenecen a personas distintas a su deudor; ello se sustenta en la naturaleza relativa de la relación jurídica obligacional; es decir, del hecho cierto que el sujeto activo de dicha relación -acreedor- solo puede formular exigencia en el cumplimiento de determinada prestación_-de dar, de hacer o de no hacer- al sujeto pasivo -deudor- de la misma relación; el incumplimiento de la obligación por el deudor, habilita al acreedor a formular ante el órgano jurisdiccional pretensiones tendientes a lograr el cumplimiento por el deudor de la obligación asumida; si la obligación es de aquellas que pueden ser apreciadas patrimonialmente, y que llegado el momento el cumplimiento se reduce al abono de una determinada suma de dinero, corresponde al acreedor solicitar al juez la afectación jurídica o gravamen de los bienes que pertenecen al deudor a efecto de que, de alcanzar sentencia firme a su favor, puedan dichos bienes ser objeto de subasta o venta pública, con el objeto de recaudar el dinero que sirva para pagar al acreedor. Tales bienes, como se indica, tienen que ser necesariamente del deudor o en todo caso, de quienes, en virtud de la ley o del convenio, deban asumir la misma obligación que el deudor incumplió.

1 LAMA MORE, Héctor Enrique. Acerca de las tercerías de propiedad contra gravámenes que provienen de garantías reales. En: http://www.jusdem.org.pe/webhechos/N010/tercerias.htm. 
Si el bien afectado jurídicamente por el juez con medida cautelar o para su ejecución -por ejemplo embargo- no pertenece al deudor, sino a una persona ajena a la relación jurídica sustantiva existente entre el demandante -acreedor- y el demandado -deudor-; corresponde a ésta persona hacer valer su derecho de propiedad a efecto de que el juez, que dictó el gravamen, detenga la subasta pública, deje sin efecto tal medida y le entregue el bien libre del mencionado gravamen. La acción que éste tercero hace valer ante el órgano jurisdiccional se conoce como la tercería excluyente de propiedad o tercería de dominio; la doctrina y los sistemas procesales contemporáneos, han establecido que el juez que debe conocer de esta acción es el propio juez que dictó el embargo o medida cautelar; es decir, el juez que conoce del proceso principal.

\section{CONCEPTO}

El artículo 533 del Código Procesal Civil ha establecido que "[l]a tercería se entiende con el demandante y el demandado, y sólo puede fundarse en la propiedad de los bienes afectados por medida cautelar o para la ejecución; o en el derecho preferente a ser pagado con el precio de tales bienes".

"La tercería de propiedad es la acción que corresponde al propietario de un bien que resulta afectado por una medida cautelar o de ejecución dictada para hacer efectiva una obligación ajena y, tiene como finalidad la desafectación del bien." ${ }^{2}$.

Para Hinostroza "la tercería (en general), estrictu sensu, es el proceso por el cual el tercero (que actúa aquí como demandante) se opone a los intereses de los sujetos activo y pasivo de la relación jurídico procesal que encierra en forma accesoria la medida cautelar que perjudica al primero de los nombrados, ya sea para exigir el levantamiento de una medida precautoria indebidamente trabada sobre un bien de su propiedad o para reclamar su derecho a ser reintegrado de su crédito de manera preferencia con el producto obtenido del remate de los bienes de su deudor afectados por una medida cautelar a favor de otro acreedor"3.

En palabras de Enrique Falcón": "se llama tercería a la pretensión independiente de un tercero ajeno al proceso, que pretende el dominio de

2 CAS No: 991-98 / HUANUCO.

3 Hinostroza MíngueZ, Alberto (2008). Procesos civiles relacionados con la propiedad y la posesión. Lima: Gaceta Jurídica, p. 321.

4 Falcón, Enrique M. (1978). Derecho Procesal Civil, Comercial y laboral. Bs. As.: Cooperadora de Derecho y Ciencias Sociales. p. 86. 
los bienes embargante sobre dichos bienes". En opinión de Lino Palacios "en términos generales, denominase tercería a la pretensión que puede interponer una persona ajena a las partes que intervienen en un determinado proceso a fin de que se disponga el levantamiento de un embargo en ese proceso sobre un proceso de su propiedad que se le reconozca al derecho a ser pagado con preferencia al embargante al producto de la venta que ha sido objeto de dicha medida".

Sin embargo, consideramos que es posible encontrar dos puntos de vista desde los cuales puede ser definida la institución bajo comentario:

\subsection{Desde el punto de vista sustantivo}

Derecho que deduce un tercero entre dos o más litigantes, reclama por un derecho propio. Punto de vista acogido en sede casatoria cuando se precisa que: "Se entiende por tercería de propiedad, aquel derecho que deduce un tercero entre dos o más litigantes, o por suyo propio, o coadyuvando en pos de alguno de ellos, teniendo por objeto el recuperar, por tercera persona, los bienes embargados que al tiempo de ejecutarse una medida de embargo eran de su propiedad". ${ }^{5}$

Podetti anota lo siguiente: “En su acepción común, aun dentro del vocabulario jurídico, tercero es una persona ajena a una relación o a una controversia suscitada entre otras.

Yo lo empleo con un significado más amplio, que es diverso del precedente. El proceso común y también considerado históricamente tiene dos sujetos: actor y reo demandado, que con el juez constituyen la trilogía romana que da origen a la idea de la relación jurídica, simples o compuestas, los sujetos clásicos son dos: actor (primus) y demandado (secundus). Pero puede intervenir voluntariamente o por llamados por las partes o por el juez, antes o después de trabado la contienda, otro sujeto (tertius) que bien puede ser como (litis consorte, coadyuvante substituto o sucesor del actor) o Demandado, pero que es siempre un nuevo sujeto distinto físicamente a los anteriores y jurídicamente también, aun cuando sea solo en matices de su interés.

A este Nuevo Sujeto, lo llamo tercerista o tercero, con el significado de que nos es Premius (actor originario) ni secundus (demandado originario). Así llamo tercerista: llamado en garantía real (real o personal) el denunciado por

5 CAS No: 1859-97 / LA LIBERTAD 28-12-1999. El Peruano 28-12-1999. p. 4424. 
ficto poseedor y todo aquel que por su interés propio directo o por defender un interés ajeno a fin defender el propio, sea ese interés originario o por cesión, sucesión o substitución, interviene en un proceso pendiente, sea como litisconsorte de los sujetos originales, en lugar de uno de los o en forma incluyente.

En resumen, cuando posteriormente a la demanda, o sea al ejercicio por el actor de la facultad de pedir protección jurídica interviene otros sujetos (fuera del demandado o demandados contra quienes se dirigió la demanda), sustituyendo coadyuvando con los sujetos principales, sostengo que hay TERCERIA. Puede haber pluralidad de actores o de demandados o no, pude haber un nuevo sujeto frente a actor o demandado originario (tertius en sentido restringido) o no. Puede haber o varios litis o controversias" 6 .

\subsection{Desde el punto de vista procesal}

Pretensión jurídica que se tramita vía proceso abreviado por el cual una tercera persona reclama ingresar en la relación jurídica procesal expresando un derecho incompatible con el remate o un derecho preferente de pago. Persona que ejecuta una acción ajena a un juicio, invocando a su favor un derecho de tercería.

Punto de vista que también es acogido en sede civil cuando se precisa que “La tercería de propiedad es la acción que corresponde al propietario de un bien que resulta afectado por una medida cautelar o de ejecución dictada para hacer efectiva una obligación ajena y, tiene como finalidad la desafectación del bien"7.

Señala Ortells Ramos que "desde el punto de vista procesal, este embargo es válido y eficaz. Esto supone que podrán acordarse las medidas de garantías del embargo trabado, que los bienes podrán ser sometidos a los procedimientos de realización forzosa previstos en la Ley y que podrán ser adjudicados los mismos. Todo ello sin que la circunstancia de no pertenecer los bienes al ejecutado repercuta, por sí sola, en la falta de validez y eficacia procesales de estos actos de ejecución ${ }^{8}$.

Podemos señalar que la tercería viene a ser aquella pretensión deducida por un tercero en un proceso, del cual no es parte sustantiva ni procesal, en cuya

\footnotetext{
6 PODETTI (1949). Tratado de tercería. Bs. As.: Ediar S.A. Editores. pp. 32-34.

CAS N ${ }^{\circ}$ : 991-98 / HUANUCO.

8 Ortells Ramos, M. Proceso Civil Práctico. Ob. Colectiva (Coord. Gimeno Sendra, V.). Madrid: Ed. La Ley, 2002. p. 969.
} 
virtud reclama el levantamiento de un embargo trabado sobre un bien de su propiedad, o el pago preferencial de su crédito con el producido de la venta del bien embargado. Estos son los únicos supuestos en que resulta posible plantear una Tercería, debiendo diferenciarse de los casos de Intervención de terceros en un proceso, que fueran mencionados anteriormente y cuyos presupuestos son mucho más amplios que los de las Tercerías.

Si señalamos la necesaria existencia de un embargo trabado sobre un bien de propiedad del tercerista, debemos dejar en claro que el embargo debe hacerse efectivo y no solo decretado, puesto que recién al hacerse efectivo el embargo ocurre la afectación del bien. También cabe mencionar que al referirnos a un Bien, incluimos en el término a los bienes inmuebles, muebles, derechos intelectuales, industriales, etc.

Existe criterios jurisprudenciales en los cuales se acepta la posibilidad de interponer la tercería en los proceso de ejecución de garantía hipotecaria, así, se señala que: “(...) la tercería... resulta factible su interposición en un proceso de ejecución de garantía hipotecaria; toda vez que, la hipoteca es un acto jurídico sustantivo, que crea un derecho real de garantía que se constituye voluntariamente, para respaldar obligaciones propias o de terceros. (...) en este caso el derecho de los terceristas, para ser opuestos al derecho del acreedor hipotecario, debía ser inscrito con anterioridad al de éste; por lo que, su trascendencia para prevalecer o no sobre la garantía real tiene que merecer análisis en sentencia" ${ }^{\prime \prime}$.

\section{FUNDAMENTO}

\subsection{La tercería en términos amplios}

El proceso, en principio, vincula solo al demandante y al demandado, pero, frecuentemente, se extiende también a terceros que pueden encontrarse afectados de dos maneras, según se trate de un proceso de conocimiento o de ejecución. Así también lo ha hecho saber nuestra Corte Suprema cuando ha precisado que; "Se entiende por tercería de propiedad, aquel derecho que deduce un tercero entre dos o más litigantes, o por suyo propio, o coadyuvando en el de alguno de ellos, teniendo por objeto el recuperar, por tercera persona, los bienes embargados que al tiempo de ejecutarse una medida de embargo eran de su propiedad"10.

\footnotetext{
9 CAS. No 1162-02 JUNIN. El Peruano: 03-02-2003. p. 9991.

10 CAS No: 1859-97 / LA LIBERTAD. El Peruano 28-12-1999, p. 4424.
} 
En el primer caso, el tercero defenderá su derecho interviniendo en la relación procesal para evitar las consecuencias de una sentencia desfavorable; en el segundo, lo hará conservando su calidad de tercero para reclamar el dominio del bien embargado, o una preferencia sobre el producido de la venta de la misma para el pago de su crédito.

\subsection{Términos a diferenciar}

En nuestro proceso judicial, el trámite se realiza entre dos partes: demandante y demandado; así también, la Sentencia resultante del litigio solo se referirá a dichos sujetos, pero suele ocurrir que la Sentencia que recaiga en el juicio pueda afectar los intereses propios de un tercero, o bien ese tercero, según las normas legales, hubiese estado legitimado para demandar o ser demandado en el juicio. Dicho de otra manera, esta persona puede tener un interés legítimo en el modo como dicha litis será decidida.

En este supuesto, aparece en la litis quien se denomina como tercero interviniente, una persona que comparece por iniciativa propia, en defensa de su patrimonio o derechos, en un pleito iniciado por otros, cualquiera sea el estado y la instancia en que se encontrare aquél.

Tercero: persona que nada tiene que ver con la relación jurídica sustancial. Ej. Contrato de compra venta. Extraño en proceso.

Tercería: persona que está legitimada para ingresar a una relación procesal. Pretensión procesal: acción procesal.

Tercerista: el juez acepta participación de tercera persona como parte del proceso.

La tercería se entiende con el demandante y demandado y solo puede fundarse en la propiedad de los bienes afectados por medida cautelar o para la ejecución; o en el derecho preferente a ser pagado con el precio de tales bienes. Al respecto FALCON precisa que la tercería de dominio es aquella “(...) en la que el tercerista reclama la propiedad de la cosa embargada"11.

Otorga una legitimación ad causam plenaria y da al interviniente el carácter de sujeto procesal primario. Se da cuando existe una relación de hecho provocada por un proceso suscitado entre otras personas y el derecho del tercerista.

\footnotetext{
11 FALCón, Enrique (1978). Derecho procesal Civil, comercial y laboral. Bs. As.: Cooperadora de Derecho y Ciencias Sociales, p. 86.
} 


\section{COMPETENCIA EN MATERIA DE TERCERÍA}

Los procesos de tercería se tramitan en la vía abreviada, conforme lo precisa el artículo $486^{\circ}$ del Código Procesal Civil. Por lo tanto los jueces competentes para su conocimiento son los civiles y los de paz letrado (artículo $488^{\circ}$ del CPC).

No obstante, en la medida de que la tercería presupone un proceso ya iniciado en el cual se encuentra pendiente la ejecución de un bien que no es de propiedad del deudor principal de la obligación incumplida (o de un tercero responsable), su trámite corresponde que lo conozca el mismo juez que conoce el proceso ya iniciado, o el juez que ordenó la medida cautelar que afecta el bien (artículo $100^{\circ}$ del CPC). Por esa razón se dice que la naturaleza de este proceso es incidental, en tanto su trámite no puede desligarse de la competencia del juez que conoce el proceso principal.

Con relación a la norma antes señalada existe un posición muy interesante por parte de la Profesora Eugenia ARIANO, para quien "Quizá la clave para determinar quien es el Juez competente esté justamente en el artículo $100^{\circ}$ del CPC, artículo en el que cayendo en un viejo equivoco, se concibe a la tercería como una "intervención de terceros", cosa que obviamente no es tal pues la tercería promueve un proceso declarativo autónomo a instancia del tercerista en contra de las partes del otro proceso y no una inserción de un ( hasta ese momento) tercero en un proceso pendiente inter alios. Pero la (quizá única) valía del artículo 100 del CPC está justamente en que al discurrir impropiamente de "intervención" nos está indicando ante quien se debe plantear la tercería como toda "intervención" ante el juez del proceso"12.

Respecto de la competencia Lama More precisa que el juez competente para conocer la demanda de tercería de propiedad es el mismo juez que tiene a cargo el proceso donde se dictó la medida cautelar o para la ejecución. No se incluye en este supuesto, el gravamen originado en una garantía real, como es el caso de la hipoteca, pues tal afectación jurídica no tiene su origen en una decisión jurisdiccional, sino en una decisión voluntaria celebrada entre el acreedor y el constituyente de la garantía o en todo caso en una disposición legal -hipoteca legal-, pues aún cuando el tercero acredite la propiedad del bien afectado con hipoteca, tal afectación no podrá levantarse en dicho proceso abreviado de tercería, pues el título registral que da origen

12 ARIANO DEHO, Eugenia. «La tercería de "propiedad” en el CPC de 1993: sus problemas y sus atajos». En: Dialogo con la Jurisprudencia. Cuadernos jurisprudenciales. №39, Primera edición. Setiembre 2004. pp. 03-17. 
al gravamen hipotecario no se origina en una decisión judicial, como es el caso del embargo o medida cautelar; en tal caso el interesado deberá acudir con una demanda -distinta a la de tercería- donde el objeto del proceso sea la ineficacia o invalidez de la garantía real; invalidada la garantía o declarada la ineficacia de tal derecho, recién se puede disponer el levantamiento de la hipoteca, lo que no es posible jurídicamente en el proceso de tercería.

Como ya ha quedado claramente establecido puede intervenir en un proceso un tercero (es decir aquel ajeno a la relación sustantiva que la originó y a la relación procesal instaurada, quien pretende se le reconozca su derecho en posición a los litigantes en dicho proceso, como consecuencia de una medida cautelar ejecutada respecto de un bien o bienes de su propiedad o respecto del cual tuviera un mejor derecho que el titular de la medida cautelar concedida. El juez de la pretensión principal resulta competente para que conozca la acción de tercería interpuesta.

\section{CLASES}

Conforme se aprecia de la norma procesal y de la doctrina, se señala la existencia de dos clases de tercería, la primera llamada tercería de propiedad (o excluyente de dominio) y la segunda llamada tercería de derecho preferente (o de pago).

\subsection{Acción de Tercería de Propiedad o de dominio}

\subsubsection{Concepto}

La tercería de propiedad es la acción que corresponde al propietario de un bien que resulta afectado por una medida cautelar o de ejecución dictada para hacer efectiva una obligación ajena y, tiene como finalidad la desafectación del bien.

Para Hinostroza la tercería de propiedad es el proceso destinado a acreditar el dominio de un bien sobre el cual recae una medida cautelar o para la ejecución dictada en otro proceso, para si lograr su desafectación por haber sido dicha medida indebidamente solicitada y decretada. Sin embrago precisa además que, la tercería de propiedad también puede ser promovida con el objeto de lograr la cancelación de las garantías reales que afectan el bien del tercero perjudicado, siempre y cuando su derecho de propiedad se encuentre inscrito con anterioridad a la afectación real en cuestión ${ }^{13}$.

${ }_{13}$ Hinostroza MingueZ, Alberto (2010). Procesos Abreviados. Tomo VIII. Lima: Jurista Editores. p. 397. 
Igualmente al respecto, Lama More señala que históricamente la tercería de propiedad o excluyente de dominio ha sido pensada con el objeto de que juez que dispuso un embargo -o medida cautelar- sobre un bien que no es del demandado, disponga su levantamiento -o desafectación- si el tercero acredita la propiedad del referido bien; ello supone el dictado de una medida provisoria de suspensión del proceso -solo respecto del bien cuya propiedad invoca el tercero-, aún cuando éste se encuentre en la etapa de ejecución, con sentencia firme; el juez competente para conocer la tercería de propiedad es el mismo que dictó la citada medida cautelar.

Al tratar la tercería de dominio, Juan Montero Aroca manifiesta lo siguiente, "Por medio de esta tercería se formula por el tercero oposición a un acto concreto de embargo, pidiendo que se levante la afección decretada sobre un bien determinado. Para ello el tercero tiene que afirmar, bien que es dueño de ese bien (y que no lo ha adquirido del ejecutado una vez decretado el embargo), bien que es titular de un derecho que, por disposición legal, puede oponerse al embargo o a la realización forzosa del bien embargado como perteneciente al ejecutado. El objeto de la tercería se reduce así al alzamiento del embargo, que es pedido por el tercerista y que es negado por el ejecutante $y$, en su caso, por el ejecutado, los cuales no pueden pedir cosa distinta ${ }^{14}$.

\subsubsection{Fundamento}

$\mathrm{Al}$ respecto debe precisarse que el sustento de esta figura está íntimamente vinculada con el derecho de propiedad, derecho real a través del cual determinado bien se encuentra sometido a la acción y voluntad de una persona. Por ello Hinostroza ${ }^{15}$ precisa que el proceso de tercería se basa en la protección del indicado derecho real, significando el ejercicio de la acción reivindicatoria cuando en alguna litis se afecten los derechos del titular. Cabe resaltar que si bien el bien sobre el cual recae la medida precautoria o para la ejecución fuese solo poseído por el sujeto procesal que la sufre en forma inmediata, será el propietario quien podrá reivindicarlo haciendo uso de la tercería de propiedad.

Para Alsina "El dominio es el derecho real en virtud del cual una cosa se encuentra sometida a la voluntad y a la acción de una persona, es exclusivo y el propietario puede impedir a terceros el uso, goce o disposición de la cosa;

\footnotetext{
14 Montero ArocA, Juan. (2001). El Nuevo Proceso Civil Ley 1/2000. 2da Edición. Valencia: Edit. Tirant Lo Blanch, pp. 763-764.

15 Hinostroza (2010). Op. Cit., p. 400.
} 
es perpetuo y subsiste independientemente del ejercicio que se pueda hacer de él. Nadie puede ser privado de su propiedad sino por causa de utilidad pública previa desposesión y una justa indemnización.

Por ello señala que: "Cuando se embargan bienes pertenecientes a un tercero, éste puede oponerse invocando su derecho de dominio, para el cual se le autoriza por la ley a deducir la acción de tercería. Pero esta es una facultad que se le acuerda, porque tratándose de inmuebles, no pierde el dominio por el hecho de que se hubiera vendido en la ejecución ya que podrá reivindicarlo del tercer adquiriente mientras su derecho no se haya extinguido por prescripción"16.

Así, también lo entiende la norma procesal artículo $533^{\circ}$ del Código en el cual se establece que la tercería se entiende con el demandante y el demandado, y solo puede fundarse en la propiedad de los bienes afectados judicialmente por medida cautelar o para la ejecución; o en el derecho preferente a ser pagado con el precio de tales bienes. Sin embargo, puede fundarse en la propiedad de bienes afectados con garantías reales, cuando el derecho del tercerista se encuentra inscrito con anterioridad a dicha afectación.

En tal sentido, la tercería de propiedad tiene por finalidad específica la desafectación de aquel bien que ha sido afectado por una medida acautelar o de ejecución dictada para hacer efectiva una obligación ajena. En este sentido, a través de la tercería de propiedad el legislador faculta al verus dominus de un bien para que pueda desafectarlo y así evitar que su bien responda por una obligación de la cual él no es el titular, como consecuencia de un proceso del cual tampoco es parte.

Si bien conforme lo señalan los artículos $100^{\circ}$ y $533^{\circ}$ del Código Procesal Civil, la tercería de propiedad tiene como finalidad que se reconozca el derecho del tercerista en oposición al de aquellos que litigan en un proceso donde un bien que se atribuye de tercero ha sido afectado por medida cautelar o se encuentra para la ejecución, situación que cuando se confronta derechos reales inscritos solo puede ocurrir si se examina la buena fe de quien inscribió primero, asunto que resulta ajeno a lo debatible en tercerías de propiedad y que origina una manifiesta inconexión lógica entre los hechos y el petitorio. Demandas con la fundamentación planteada ante el inferior en grado llevan

16 ALsina, Hugo (1963). Tratado teórico práctico de Derecho procesal civil y comercial. Tomo III. Bs. As.: Compañía argentina de Editoriales S.R.Ltda. pp. 346-347. 
in sito el cuestionamiento al acto jurídico contenido en el documento que encierra a la garantía real (por nulidad absoluta o por anulabilidad), lo que tampoco es materia del proceso de tercería de propiedad, ratificándose con esto la presencia, en todo caso, de la precitada causal de improcedencia en el inciso 5 del artículo $427^{\circ}$ del Código Procesal Civil.

\subsection{Condiciones de la acción de tercería de dominio}

Los artículos $533^{\circ}$ y $535^{\circ}$ del Código Procesal Civil establecen los presupuestos, tanto objetivos como subjetivos, cuya concurrencia determina la obtención de la tutela judicial correspondiente a la tercería de dominio. Dentro de dichos presupuestos podríamos distinguir aquellos relativos a la admisibilidad de la demanda de tercería; y aquellos relativos al fondo de la pretensión.

\subsubsection{Presupuestos relativos a la admisibilidad de la demanda}

Señala el artículo $535^{\circ}$ de la norma procesal que: "La demanda de tercería no será admitida si no reúne los requisitos del Artículo $424^{\circ}$ y, además, si el demandante no prueba su derecho con documento público o privado de fecha cierta, en su defecto, si no da garantía suficiente a criterio del Juez para responder por los daños y perjuicios que la tercería pudiera irrogar." Así pues, podemos señalar que, con carácter previo al pronunciamiento sobre el derecho de tercerista, y como requisitos para la admisibilidad de la demanda, deben concurrir los siguientes:

\subsubsection{Un principio de prueba por escrito del fundamento de la pretensión del tercerista}

Se trata, en definitiva, de que junto con la demanda se acompañe medio probatorio suficiente (documento público o privado señala la norma) que permita, sin prejuzgar el fondo del asunto, poner de manifiesto al magistrado la titularidad del tercerista sobre el bien o derecho embargado. Como señala Ortells Ramos "nos hallamos ante un especial requisito de admisión de la demanda, cuya exigencia está justificada porque la repercusión que la admisión de la tercería tiene sobre la ejecución -suspensión de la actividad ejecutiva sobre los bienes y derechos a los que se refiera- hace aconsejable que el tercerista acredite que su pretensión cuenta con un mínimo de fundamento"17.

17 Ortells Ramos, M. (2002). Proceso Civil Práctico. Ob. Colectiva (Coord. GimenO Sendra, V.). Madrid: Ed. La Ley, p. 980. 
Dicho requisito de admisibilidad de la demanda no debe confundirse con la obligación de la parte de acompañar a su escrito de demanda todos aquellos documentos en que la misma sustente su pretensión, ni con la idea de que la aportación documental inicial sea el único medio para probar el fundamento de la pretensión.

Para oponer con éxito una tercería excluyente resulta imprescindible que se acredite que la fecha de adquisición sea cierta y confiable y que preceda en el tiempo a la de medida cautelar.

Conforme señala Rodríguez Garcés ${ }^{18}$ "el tercerista debe probar de acuerdo con las reglas generales su derecho de dominio sobre los bienes embargados. Debe probar que la cosa embargada es la que reclama, y precisar la identidad de ella en tal forma que lleve al convencimiento del juez que lo que se reclama y le pertenece es precisamente el objeto embargado y no otro".

Al demandante le corresponde acreditar en los actos postulatorios de su pretensión de manera plena su derecho de propiedad. En tal sentido debe tenerse en cuenta que en el caso de bienes muebles el accionante acreditará su derecho con la correspondiente escritura pública o Copia Literal de dominio en la que se pueda corroborar dicha afirmación. En el caso de bienes muebles deberá bastará con que se pueda establecer la posesión del bien, la misma que detentaba al momento de la ejecución de la medida cautelar dispuesta.

$\mathrm{Al}$ respecto Alsina ${ }^{19}$ precisa que: "cuando lo embargado fuese mueble es necesario hacer un distingo. Si el tercerista se encontraba en posesión de la cosa en el momento del embargo, probada la posesión corresponde hacer lugar a la tercería, porque el poseedor tiene a su favor la presunción de la propiedad. Aunque ninguno de los documentos presentados para justificar la posesión prueben por si solos la verdad de la fecha expresada en ellos, respecto de terceros, el conjunto de indicaciones concordantes que ellos suministran autoriza la procedencia de la tercería deducida si no hay antecedentes b de la posesión anterior del ejecutado".

La acreditación del derecho de propiedad debe encontrase debidamente sustentada en documento idóneo en el cual se pueda corroborar el derecho

\footnotetext{
18 Rodriguez Garces (1967). Tratado de tercerías. Tomo I. Segunda Edición. Concepción: Libotec Ltda. Editores. p. 309 .
} 
del tercerista, así en el caso que el demandante presente una minuta de compra venta que no se encuentre legalizada o certificada por notario, no otorga el sustento necesario al Juez para que admita a trámite la demanda, así, en sede casatoria se ha señalado que "La tercerista pretende acreditar su derecho con una minuta (...), la que no se encuentra legalizada o certificada notarialmente no bastando la existencia de un sello de la Notaría, por lo que dicho documento no puede ser oponible al derecho de terceros" 20 .

Igualmente, resulta improcedente la demanda de tercería si el demandante no acredita la propiedad del bien inmueble a la fecha de formalización de la medida de embargo en forma de inscripción del referido inmueble.

De igual forma en sede casatoria se ha precisado que: "La desafectación de un gravamen hipotecario no puede lograrse a través de un proceso de tercería, sino en uno de nulidad de acto jurídico. Ya que la tercería de propiedad, tiene como presupuesto procesal fundamental que se acredite la propiedad de los bienes afectados o bien en el derecho preferente a ser pagado con el precio de tales bienes" ${ }^{21}$.

\subsubsection{La existencia del embargo sobre bienes y derechos}

Pese a que resulta evidente la existencia de este requisito, habida cuenta que la finalidad de la tercería de dominio es que se deje sin efecto el embargo indebidamente trabado, lo cierto es que el artículo $534^{\circ}$ de la norma procesal establece unos límites temporales a la interposición de la tercería de dominio. Según ella la tercería debe ser interpuesta en cualquier momento antes de que se inicie el remate del bien, el momento inicial debe situarse en el momento en que se haya embargado el bien o bienes a que se refiere, aunque el embargo sea preventivo, pero que incluso se encuentre en ejecución y para su correspondiente remate. En este sentido, y para atender al momento concreto del embargo hay que acudir al artículo $611^{\circ}$ de la norma procesal que establece el contenido de la decisión cautelar así como el artículo 638 y $641^{\circ}$ referido a la ejecución de la medida efectuada por funcionario público o realizada por secretario respectivo.

El momento final, como indica el apartado segundo del artículo $534^{\circ}$ en relación a la tercería de propiedad puede realizarse en cualquier momento

\footnotetext{
19 Alsina (1963). Op. Cit., p. 351.

20 CAS. N. 125-2000 / LA LIBERTAD.

21 CAS. No. 444-2004 LAMBAYEQUE El Peruano, 01-06-2006.
} 
hasta antes de que se inicie el remate del bien y para el supuesto de derecho preferente hasta antes que se realice el pago al acreedor.

No obstante, si durante la sustanciación del procedimiento de tercería, el embargo es alzado mediante resolución firme, nos encontraremos ante una carencia sobrevenida del objeto por lo que, el procedimiento de tercería finalizará al haberse sustraído la materia.

Lino Palacio 22 al respecto apunta que: "la admisibilidad de las tercerías cualquiera sea su clase, se haya condicionada a la existencia de un embargo. En caso contrario no existiría interés jurídico que la sustentase, porque aun en la hipótesis de que en un proceso pendiente entre otras personas la controversia versará sobre un proceso pendiente entre otras personas la controversia versará sobre el dominio de un bien de propiedad del tercerista, o sobre un crédito de éste relacionado con la cosa litigiosa, la sentencia que en ese proceso se dictará le sería inoponible y carecería por tanto de toda virtualidad para despojarlo del bien o de un derecho preferencial sobre él.

No basta, por otra parte, que el embargo haya sido ordenado, Además es necesario que haya sido efectivamente trabado. Cabe señalar asimismo, que la jurisprudencia ha extendido la admisibilidad de tercerías frente a la existencia de otra clase de medidas o situaciones procesales cuyas consecuencias equivalen esencialmente a las del embargo. De allí que se haya decidido que la pretensión de tercería puede ser interpuesta con motivo del secuestro".

\subsubsection{Prestación de caución}

El Código Procesal Civil, en la parte final del artículo $535^{\circ}$ establece un tercer presupuesto de admisibilidad de la demanda de tercería que no es exigible en todo caso, sino cuando no se haya acreditado el derecho por parte del demandante con documento privado o público, por lo que a criterio del juez deberá otorgar garantía suficiente.

Se trata, en definitiva, tal y como señala Montero Aroca "de proteger al acreedor frente a las dilaciones provocadas por demandas abusivas o carente de fundamento y de asegurarle, en su caso, un adecuado resarcimiento por el perjuicio que ello pudiere ocasionarle" ${ }^{\prime 23}$.

\footnotetext{
22 Palacio Lino (1983). Derecho Procesal Civil. Tomo III. Tercera reimpresión. Bs. As.: Abeledo Perrot, p. 276.

${ }^{23}$ Montero ArocA, J y Otro (2004). La tercería de dominio. Valencia: Ed. Tirant lo Blanch. p. 309.
} 
Consideramos en este caso que a criterio del Juez aplicando supletoriamente la norma relativa a la contracautela, podrá disponer que se preste una de naturaleza real o personal. En este último caso se puede incluir a la caución juratoria, la que podrá ser admitida siempre que esta sea proporcional y eficaz.

Si se presenta una garantía de naturaleza personal esta deberá ser ofrecida en el escrito de tercería, siendo requisito necesario la legalización de la firma ante el secretario o especialista legal respectivo.

En el caso de la garantía de naturaleza real se constituye con el mérito de la resolución que admite la tercería y recae sobre los bienes de propiedad de quien la ofrece, no pudiendo ser el mismos o los mismos objeto de tercería, en tal sentido el Juez remitirá el oficio respectivo para su inscripción en el registro correspondiente.

\subsubsection{Presupuestos relativos al fondo de la pretensión}

Señala el artículo $533^{\circ}$ de la norma procesal que: “La tercería se entiende con el demandante y el demandado, y sólo puede fundarse en la propiedad de los bienes afectados judicialmente por medida cautelar o para la ejecución; o en el derecho preferente a ser pagado con el precio de tales bienes. Sin perjuicio de lo señalado, puede fundarse en la propiedad de bienes afectados con garantías reales, cuando el derecho del tercerista se encuentra inscrito con anterioridad a dicha afectación".

A tenor de la redacción de dicho artículo se puede hablar de tres requisitos relativos al fondo de la pretensión:

\subsubsection{No tener la condición de parte en la ejecución}

No solo tienen la condición de tercero el sujeto que es ajeno al procedimiento principal, sino aquel que es extraño a la deuda que mantienen ejecutante y ejecutado.

Tal como señala Montero Aroca, "el actor de la tercería ha de tener necesariamente la condición de tercero respecto del proceso de ejecución, lo que significa que no tiene legitimación quien ya es parte en ese proceso o sujeto pasivo de la ejecución forzosa" 24 .

\footnotetext{
${ }^{24}$ Montero Aroca. Op. Cit., p. 94.
} 
Pero ser parte en la ejecución no es estar personado como tal en la misma, sino como ha señalado Ortells Ramos "no haber sido puesto en la posición de partes ejecutadas como consecuencia de la actividad ejecutiva" 25 .

En definitiva quedan excluidos no solo aquellos supuestos en que la ejecución se ha despachado frente a una persona (ejecutado) sino también aquellos que, tal y como señala la norma procesal, se han visto afectados por una extensión de la responsabilidad en la vía ejecutiva, "al ser propietarios de los bienes especialmente afectos al pago de la deuda en cuya virtud se procede".

\subsubsection{Tener la calidad de propietario o titular del bien o derecho materia de embargo}

Como establece la norma procesal la tercería solamente puede fundarse en la propiedad de los bienes afectados judicialmente o para la ejecución.

Así, pues, la tutela de la tercería de dominio no solo puede concederse al titular de un derecho de propiedad sobre el bien embargado sino a aquellos otros titulares de derechos, distintos del de propiedad, pero susceptibles de ser objeto de un embargo indebido (v.gr. titularidad de cuentas bancarias, derecho de usufructo, derecho de copropiedad, etc.). No obstante lo anterior, lo cierto es que la gran mayoría de los supuestos que en la práctica originan el planteamiento de una tercería de dominio tienen como base el derecho de propiedad.

En relación con lo señalado, es importante precisar que el tercerista debe acreditar que en la adquisición de su derecho han concurrido todos los requisitos exigidos por la legislación civil para que tenga lugar dicha adquisición y, en particular, cuando se trate de adquisiciones derivativas, y por actos ínter vivos, que hayan concurrido el título y el modo.

El derecho de posesión también puede ser considerado título que acredite la propiedad si se tiene en cuenta la presunción legal de la misma, de igual forma lo ha precisado la Corte Suprema ${ }^{26}$ cuando señala que: "El derecho de propiedad es el poder jurídico que permite usar, disfrutar, disponer y reivindicar un bien; y que además, los bienes muebles se transfieren por tradición y que existe presunción de propiedad de aquel qué de buena fe y como propietario recibe la posesión de la cosa mueble".

\footnotetext{
25 ORTELLS. Op. Cit., p. 975.

26 CAS. N 1066-03-UCAYALI.
} 
Para Ramiro Podetti, quien comentando el requisito sobre el cumplimiento de formas legales de la demanda en el juicio de tercería, entre nosotros el artículo 535 del CPC, expresaba: "El título al cual se refieren estas disposiciones legales, no es necesariamente el título traslativo de dominio, otorgado de acuerdo con las prescripciones legales sino el que prima facie, acredite el derecho del tercerista (no olvidemos que estamos tratando aquí solo la admisibilidad de la demanda)" 27 .

La tercería de propiedad es una pretensión propia del tercero afectado con medida cautelar o para la ejecución, y como tal, no constituye una petición al interior de este proceso. En sede casatoria se ha preciado que es nula la resolución, que pronunciándose sobre el fondo de la controversia, declara improcedente de plano la demanda, pues, debe verificar si cumple los requisitos del artículo $534^{\circ}$ y $535^{\circ}$ del Código Procesal Civil para su admisibilidad.

En efecto se trata de un requisito de admisibilidad, no siendo necesario que el documento acredite de manera incontrovertible el derecho invocado del tercerista, pues el juez deliberará sobre esto en la etapa procesal correspondiente. Recordemos que "el juez, lo mismo que el historiador, está llamado a indagar sobre los hechos del pasado y a declarar la verdad de los mismos; del juez, como del historiador, se dice también que no debe llevar a cabo una labor de fantasía, sino una obra de elección y de construcción sobre datos preexistentes. En la historia y en el proceso se habla de pruebas, de documentos, de testimonios, de fuentes, y de su crítica" ${ }^{28}$.

\subsubsection{Adquisición del bien o derecho con anterioridad a la afectación del embargo}

La exigencia de este requisito es evidente, toda vez que la anotación de embargo no limita las facultades de disposición del titular del bien embargado. Ahora bien, debido a que la transmisión de bienes o derechos embargados es perfectamente posible y válida en el ámbito de las relaciones jurídicas y, en virtud del principio de seguridad jurídica, esa transmisión no puede perjudicar la expectativas de cobro del acreedor ejecutante, ni amparar la sustracción de un bien del deudor perseguido en un procedimiento de ejecución.

\footnotetext{
27 PODETTI, Ramiro (2004). Tratado de la tercería. Tercera edición ampliada y actualizada por Víctor Guerrero Leconte. Bs. As.: Editorial Ediar, p. 80.

28 CAlamandrei, Piero (1945). Estudios sobre el proceso civil. Traducción de Santiago Sentís Melendo. Argentina: Editorial Bibliográfica, p. 107.
} 
Pero no basta que el tercerista sea propietario o titular del derecho embargado en el momento de la interposición de la tercería, sino que como señala la norma procesal, y como venía exigiendo la Jurisprudencia, ha de serlo en el momento anterior a aquel en que se produzca el embargo, con independencia del momento en que se le de publicidad a la misma. En este sentido, debe tenerse en cuenta que una vez que se haya ejecutado la medida cautelar existe la posibilidad de que el afectado con la misma pueda interponer su pretensión.

En definitiva, la prevalencia entre el derecho del tercerista y el del acreedor ejecutante, vendrá determinada por el momento cronológico en que se produjo la adquisición de bien o derecho y aquel en que se produjo el embargo y, ello, con independencia de la publicidad registral.

No hay que olvidar, tal y como antes se ha dicho que la adquisición de la propiedad y demás derechos exige la concurrencia del título y de la tradición, en cualquiera de sus modalidades antes de que se haya producido el embargo.

En sede casatoria ${ }^{29}$ se ha precisado que el Derecho del tercerista debe ser inscrito con anterioridad al del acreedor hipotecario Para oponer el derecho de los terceristas al derecho del acreedor hipotecario, debía ser inscrito con anterioridad al de éste; por lo que, la trascendencia de aquél derecho para prevalecer o no sobre la garantía real tiene que merecer análisis en sentencia.

De igual forma si al haberse decretado la medida de embargo y encontrarse esta inscrita con anterioridad a la compraventa efectuada, no resulta amparable la tercería, toda vez que para poder oponer derechos reales es necesario que el derecho se encuentre inscrito con anterioridad al de aquel que se opone.

\subsection{Tercería de mejor derecho o tercería de pago}

\subsubsection{Concepto}

Llamada también tercería de Mejor Derecho o derecho preferente, y de igual derecho, llamada también coadyuvante, es aquella en la que el tercerista no alega ser propietario de los bienes en litigio, sino tener sobre ellos un

${ }^{29}$ CAS. No $1162-02$ JUNIN El Peruano, 03/02/2003. 
derecho preferente al que pretenden los litigantes. Tiene por objeto lograr que el tercerista sea reintegrado de su crédito con los bienes embargados, y con preferencia al acreedor ejecutante.

Para ALSINA ${ }^{30}$, "la tercería de mejor derecho tiene por objeto reclamar el pago de un crédito, con preferencia al del ejecutante, una vez realizados los bienes embargados. La preferencia puede resultar, en primer término de la existencia de un privilegio especial, o sea de la situación legal en que un crédito se encuentra con relación a otro frente a determinados bienes. (...) Pero, además de los privilegios, existe otra causa de preferencia que es el embargo; pues, como hemos visto, la fecha de sus inscripción en el registro de la Propiedad tratándose de inmuebles o de la notificación si fuesen créditos, determina la prelación para el pago".

En tal sentido, esta clase de tercería denominada mejor derecho, por la que se pretende tener un crédito que debe ser pagado con preferencia al del ejecutante con el producto de la venta del bien embargado. Así también se ha precisado en reiterada jurisprudencia en sede casatoria respecto del pago de remuneraciones: Prioridad. "El pago de las remuneraciones y de los beneficios sociales del trabajador tiene prioridad sobre cualquiera otra obligación del empleador. El artículo primero del Decreto Legislativo ochocientos cincuenta y seis señala que constituyen créditos laborales: i) las remuneraciones, ü) la compensación por tiempo de servicios, iii) las indemnizaciones, iv) en general, los beneficios establecidos por ley que se adeudan a los trabajadores, v) los aportes impagos tanto del Sistema Privado de Administración de Fondos de Pensiones como del Sistema Nacional de Pensiones, y los intereses y gastos que por tales conceptos pudieran devengarse" ${ }^{\prime 1}$.

\section{OPORTUNIDAD}

Con arreglo al artículo $534^{\circ}$ del Código Procesal Civil, la tercería de propiedad puede interponerse en cualquier momento antes que se inicie el remate del bien; es decir, el verdadero propietario del bien puede interponer la demanda de tercería de propiedad, aun cuando el bien afectado haya sido convocado a remate, pero no adjudicado, logrando de esta forma la suspensión del remate y la correspondiente desafectación del bien.

\footnotetext{
30 Alsina, Hugo (1963). Op. Cit. Pp. 355-356.

31 CAS N ${ }^{\circ} 752-05$ SANTA.
} 
Para Pietro Castro y Ferrándiz citado por Hinostroza ${ }^{32}$ "La demanda (de tercería de dominio) se ha de presentar dentro del tiempo conveniente para que sea útil, esto es, antes de que se haya otorgado la escritura de venta de los bienes embargados o se haya consumado ésta a favor del rematante, o se haya entregado al acreedor en adjudicación para pago. Pasados estos momentos preclusivos el tercero solo podrá hacer valer su derecho sobre los bienes mediante la correspondiente persecución civil o penal".

En sede civil se ha precisado que: "La tercería de propiedad puede interponerse en cualquier momento antes que se inicie el remate del bien, debiendo entenderse por inicio del remate, la lectura de la relación de bienes a venderse, al acto mismo de la venta y posterior adjudicación en propiedad a favor de algún postor, que se producen en el mismo acto" ${ }^{\prime 33}$.

Se trata de un recurso de casación interpuesto por la causal prevista en el inciso 3 del artículo 386 del Código Procesal Civil, relativa a la contravención de normas que garantizan el debido proceso. Estableciendo el recurrente que su demanda de tercería no ha sido presentada irregularmente. Los Magistrados de la Corte Suprema, al resolver la presente causa señalaron, que la tercería de propiedad puede interponerse en cualquier momento antes que se inicie el remate del bien, debiendo entenderse por inicio del remate, la lectura de la relación de bienes a venderse, al acto mismo de la venta y posterior adjudicación en propiedad a favor de algún postor, que se producen en el mismo acto. En consecuencia, al haberse presentado la demanda de tercería con anterioridad a este acto, se entiende que ésta ha sido interpuesta oportunamente. Por tal razón, la Sala declaró fundado el recurso de casación interpuesto por el recurrente.

Igualmente, en el caso en el cual el bien se encuentre sujeto a ejecución (en remate) del bien, se señaló que: "Debe entenderse que la interposición de la tercería excluyente de dominio puede efectuarse hasta antes de que se inicie el acto de remate, esto es, hasta antes de que se de lectura de la relación de bienes y condiciones del remate, y no hasta antes de que se adjudique el bien a uno de los postores ${ }^{34}$. Es decir, que el inicio del acto de remate se da con la lectura de los bienes y condiciones en los que se va a realizar el citado acto, por lo que resulta pertinente platear la tercería hasta dicho momento y no con posterioridad caso contrario no será ampara la pretensión del tercerista.

\footnotetext{
32 Hinostroza (2010). Op. Cit., p. 403.

33 CAS. 181-2002-LAMBAYEQUE, El Peruano 30-06-2003.

34 CAS. N 1064-2000 (Publicada el 30 de noviembre del 2000).
} 


\section{EFECTOS DE LA TERCERÍA DE PROPIEDAD}

Tal como se ha venido señalado en líneas anteriores, la tercería de propiedad constituye un proceso a través del cual un tercero afirma: Que es titular del derecho de propiedad sobre el bien embargado o en ejecución en otro proceso; $\mathrm{y}$, que su derecho de propiedad es oponible al derecho del acreedor demandante. El objeto consiste en que el Juez ordene la desafectación de bien que afirma le pertenece. En tal sentido, podría señalarse como naturaleza. La tercería es un proceso no una intervención de terceros.

Respecto de los efectos del auto que admite la demanda de tercería de propiedad, la norma establece dos situaciones:

1) Si el tercerista acredita su derecho de propiedad con documento público o privado de fecha cierta. Admitida la tercería de propiedad, se suspenderá el proceso si estuviera en la etapa de ejecución, aunque esté consentida o ejecutoriada la resolución que ordena la venta de los bienes. En los casos que los bienes estén sujetos a deterioro, corrupción o desaparición o que su conservación resulte excesivamente onerosa, el producto de la venta queda afectado al resultado de la tercería.

2) Si el tercerista no acredita su derecho de propiedad con documento público o privado de fecha cierta, el tercerista puede obtener la suspensión de la medida cautelar o de la ejecución del bien afectado, si la garantía otorgada es suficiente a criterio del Juez.

Para Hinostroza, La admisión de la demanda de tercería de propiedad no suspende la tramitación del cuaderno cautelar, sino del proceso principal, siempre que éste se encuentre en está de ejecución forzada y no se haya dado inicio al remate. La suspensión opera entonces - en forma automática. A partir del requerimiento que hace el juzgado al demandado para que cumpla lo ordenado en la sentencia firme; de ningún modo tiene lugar antes de dicho momento procesal. esto se explica porque la tercería de dominio tiene por finalidad principal evitar la venta forzosa de los bienes del tercerista y el alzamiento de la medida cautelar indebidamente trabada, lo que no avala la dilación del proceso principal en relación al cual se solicitó y dispuso una medida cautelar.

De igual forma señala que, la suspensión de la mediada cautelar que puede obtener el tercerista en caso que no acredite que los bienes son de su propiedad obedece no tanto al objeto de la tercería, sino más que todo a la garantía 
que presta con la finalidad de asegurar el resarcimiento de los daños que pueda causar tal suspensión. Es en virtud de esta garantía que se suspende la medida preventiva, siempre que sea suficiente para cubrir la obligación. Al respecto se precisa que: "El perjudicado por una medida cautelar dictada en el proceso que no es parte, puede pedir su suspensión sin interponer tercería, anexando título de propiedad registrado.

Si las facturas, guías y boletas de venta que acompañen no acreditan de modo alguno la propiedad alegada, debe el accionante hacer valer su derecho a través de la tercería" 35 .

Si resultara fundada la demanda de tercería de propiedad interpuesta por el propietario del bien afectado, el juez ha de decretar el levantamiento de la medida cautelar dispuesta y cesa la suspensión del proceso principal, debiendo la parte ejecutante solicitar la afectación de otros bienes para segurar o proseguir con le ejecución forzada.

Caso contrario, si fuese declara infundada la demanda de tercería de propiedad cesa de igual forma la suspensión del proceso principal, continuándose con la prosecución del la ejecución forzada respecto de los bienes que fueron objeto de tercería, sin perjuicio de las responsabilidades civil y penal que hubiere lugar por parte del tercerista, el pago de las cotas y costos del proceso, la multa y además la ejecución de la garantía si con la demanda incurrió en daños y perjuicios para el ejecutante.

Para Solís se puede agrupar los efectos de la siguiente manera: 1) Efectos de la admisión de la tercería.- La admisión de la demanda de tercería produce la suspensión del proceso si estuviera en la etapa de ejecución, así lo establece el artículo $536^{\circ}$ del Código Procesal. Entiéndase entonces que, si el proceso no estuviera en la etapa de ejecución, la demanda de tercería no producirá la suspensión del proceso. Igualmente, el artículo 598 ${ }^{\circ}$, inc. 3, de la Ley de Enjuiciamiento Civil española establece como efecto de la admisión de la tercería, el tema de la mejora de embargo, situación que no ha sido considerado por nuestro Código Procesal Civil, lo cual creemos que debería corregirse, pues la demanda de tercería pone en peligro la venta del bien y, consecuentemente, la obtención del dinero con el cual el ejecutante espera ver satisfecho el pago de su acreencia. 2) Efectos de la estimación en la sentencia

\footnotetext{
35 Exp. N 464-97, Cuarta Sala Civil, Corte Superior de Justicia, Ledesma Narváez, Marianella, Jurisprudencia Actual, Tomo 1, Gaceta Jurídica, p. 502.
} 
de la demanda de tercería.- Si la demanda de tercería es declarada fundada, entonces se levantará el embargo y/o secuestro decretados contra los bienes del tercerista. Montero Aroca señala que lo más importante de la sentencia que decide la tercería es que su pronunciamiento principal es el relativo a la procedencia del embargo y a los únicos efectos de la ejecución en curso. Para efectuar ese pronunciamiento puede ser necesario tener que pronunciarse, de modo lógicamente previo, sobre la pertenencia del bien, pero este otro pronunciamiento no producirá cosa juzgada, por lo que es posible un proceso posterior.

En sede civil se ha precisado al respecto que: "La Sala Superior ha resuelto revocar la sentencia apelada y reformándola declaró fundada la demanda (de tercería de propiedad); en consecuencia, dispuso la suspensión del remate del inmueble sub litis; (...) en ese contexto la suspensión del remate ordenada en autos implica que este quede sin efecto de modo definitivo, ya que uno de los fundamentos de la acción de tercería es el derecho de propiedad." ${ }^{36}$ Las negritas son nuestras.

Como ya hemos señalado los efectos de la tercería solo se producirán cuando la demanda sea admitida. A partir de la expedición del auto admisorio se suspenderá el proceso si estuviera en la etapa de ejecución, aunque la resolución que ordena la venta de los bienes esté consentida o ejecutoriada (artículo 536 ${ }^{\circ}$, primer párrafo del Código Procesal Civil), esto es una resolución sobre la que no proceda ningún medio impugnatorio o sobre la cual no exista órgano jurisdiccional superior competente para cuestionarla.

En caso de que los bienes afectados estén sujetos a deterioro, corrupción o desaparición o que su conservación resulte excesivamente onerosa, el efecto de la admisión de la tercería recaerá sobre el producto de su venta y en esa medida el monto quedará condicionado al resultado de la tercería (artículo $536^{\circ}$, primer párrafo, del Código Procesal Civil). Ahora bien, si el tercerista no ha llegado a acreditar de manera fehaciente que los bienes afectados son de su propiedad, puede obtener la suspensión de la medida cautelar o de la ejecución del bien afectado si es que otorga al Juez una garantía ( la cual permite respaldar el derecho del acreedor de ver satisfecho su crédito, en la medida de que cabe la posibilidad de que la tercería sea declarada infundada) siempre que, a criterio del magistrado resulte suficiente (artículo $536^{\circ}$, segundo párrafo del Código Procesal Civil). Por ello, “Es infundada el

${ }_{36}$ CAS No 384-2004-JUNIN El Peruano 01-12-2005. pp. 15107-15108. 
pedido de desafectación de los bienes materia de medida cautelar si no se ha acreditado fehacientemente que los bienes pertenecen a persona distinta al demandado" ${ }^{37}$.

Conviene precisar que la suspensión de una medida cautelar también puede ser obtenida sin necesidad de iniciar un proceso de tercería por un sujeto que no forma parte del proceso, siempre que acredite su propiedad con título registrado. La resolución que suspenda la medida es irrecurrible, sin embargo, si el pronunciamiento del juez no es favorable para el interesado todavía le queda la opción de interponer una tercería de acuerdo con lo dispuesto por al artículo 533 (artículo 539 del Código Procesal Civil).

En sede civil, se ha señalado que: "El perjudicado con una medida cautelar dictada en proceso en que no es parte, puede pedir la suspensión sin interponer tercería, anexando el título de propiedad registrado. Se presume que el poseedor es reputado propietario, mientras no se pruebe lo contrario; ante tal presunción, corresponde al ejecutante demostrar que el bien del tercero no le pertenece a este, sino al deudor" ${ }^{\prime 38}$.

\section{CONCLUSIONES}

- La tercería viene a ser aquella pretensión deducida por un tercero en un proceso, del cual no es parte sustantiva ni procesal, en cuya virtud reclama el levantamiento de un embargo trabado sobre un bien de su propiedad, o el pago preferencial de su crédito con el producido de la venta del bien embargado.

- El sustento de esta figura está íntimamente vinculada con el derecho de propiedad, derecho real a través del cual determinado bien se encuentra sometido a la acción y voluntad de una persona.

- La tercería de propiedad puede interponerse en cualquier momento antes que se inicie el remate del bien, debiendo entenderse por inicio del remate, la lectura de la relación de bienes a venderse, al acto mismo de la venta y posterior adjudicación en propiedad a favor de algún postor, que se producen en el mismo acto.

\footnotetext{
37 Exp. N" 2276-95, Cuarta Sala Civil, Ledesma Narváez, Marianella, Ejecutorías, Tomo 4, Cuzco, 1996, pp. 357358.

38 Exp. N" 1089-98, Segunda Sala Civil, Ledesma Narváez, Marianella, Jurisprudencia Actual, Tomo 2, Gaceta Jurídica, pp. 511-512.
} 